abnormal range, (sodium greater than $60 \mathrm{mmol} / \mathrm{l}$, chloride greater than $70 \mathrm{mmol} / \mathrm{l}$ ).

Results of sweat tests performed while subjects were taking oral flucloxacillin also showed a clear demarcation between the two groups (figure). There was no significant difference between the two sets of results-that is, on and off flucloxacillin (Wilcoxon signed rank test: $p>0.5$ ) in either group.

\section{Discussion}

It has been suggested that substitution of the chloride ion by cloxacillin may occur and artefactually produce unusually low sweat chloride results ${ }^{1}$ causing difficulty in confirming the diagnosis of cystic fibrosis. Our study disproves this hypothesis and confirms that there is no contraindication to sweat testing while a subject is taking oral flucloxacillin.

The possibility that the artefactually low chloride results were due to analytical interference exists as our method differs from that (modified Schales and Schales) used by Griffiths. We would, however, reiterate that sweat tests should be performed by experienced laboratory staff with measurement of both sodium and chloride ions. Results must always be considered in the light of clinical findings as well as the age of the patient to avoid misdiagnosis of cystic fibrosis.

Further work is required to ensure that other commonly used antibiotics do not interfere with sweat test results.

\section{References \\ 1 Griffiths AD, Bull FE. Anomalous sweat chloride levels in cystic fibrosis during antibiotic therapy. Arch Dis Child 1972;47: $132-4$. \\ 2 Shwachmann $\mathrm{H}$, Kulczycki L. Long-term study of one hundred five patients with cystic fibrosis. Am J Dis Child 1958;96:6-15. \\ ${ }^{3}$ Orenstein DM, Boat TF, Stern RC, et al. The effect of early diagnosis and treatment in cystic fibrosis. Am J Dis Child 1977;131:973-5. \\ ${ }^{4}$ George L, Norman AP. Life tables for cystic fibrosis. Arch Dis Child 1971;46:139-43. \\ 5 Gibson LE, Cooke RE. A test for concentration of eletrolytes in sweat in cystic fibrosis of the pancreas, utilising pilocarpine by iontophoresis. Pediatrics 1959;23:545-9.}

Correspondence and requests for reprints to Dr J Williams, Institute of Child Health, Francis Road, Birmingham B16 8ET.

Accepted 12 February 1988

\title{
Mineral content of rib bone in infant deaths
}

\section{S W RYAN, ${ }^{*}$ S VARIEND,$\dagger$ J JAMES, ${ }^{*}$ P J CONGDON,${ }^{*}$ A HORSMAN, $\ddagger$ AND J TRUSCOTT $\ddagger$}

${ }^{*}$ Regional Neonatal Intensive Care Unit, The General Infirmary, Leeds, +Department of Histopathology, Children’s Hospital, Sheffield, and $¥ M R C$ Bone Mineralisation Group, Department of Medical Physics, The General Infirmary, Leeds

SUMMARY The mineral content of rib bone in infants who died unexpectedly was similar to that among those who died after acute illnesses, and it was significantly associated with both crown to heel length and age. In those dying from chronic illnesses it was lower than in the other two groups.

Unexplained death in infancy is thought to be caused by more than one disease. The process that results in some cot deaths may be active for a considerable time beforehand: infants may not gain weight properly before death,' and retardation of growth of the costochondral junction has been shown histologically in specimens taken at necropsy from such infants. ${ }^{2}$ We used single photon absorptiometry to measure the mineral content of the ribs near the costochondral junction to find out if histological changes in cartilage at necropsy are associated with reduced mineral content of the ribs in these infants.

\section{Patients and methods}

We studied 92 consecutive necropsies undertaken in children under the age of 2 at the Children's Hospital, Sheffield between October 1985 and February 1987. Details recorded included age at death in days (corrected for prematurity), sex, crown to heel length, and weight. They were divided into three groups according to type of diagnosis; unexplained death $(n=62)$, death after a sudden acute illness in a previously well child $(n=18)$, and death after a chronic illness $(n=12)$.

In all cases specimens of the right fifth rib including the costochondral junction were taken and stored and transported in a buffered calcium forma- 
lin solution to prevent deterioration of the mineral content. Single photon absorptiometry was carried out as previously described. ${ }^{3}$ Each rib was scanned $1.5 \mathrm{~cm}$ from the costochondral junction unless it was shorter than that, when it was scanned at its midpoint. As each rib specimen was ellipsoidal, it was measured at its widest point with calipers. For each rib, the mineral content was divided by its width to provide a size-corrected measure of the mineral content of the bone.

\section{Results}

Fig 1 shows a scattergram of the mineral content of rib against crown to heel length for all cases. Fig 2 shows regression lines of the mineral content of ribs plotted against crown to heel length for the three groups. The mean mineral content of the bone in the group of unexplained deaths was $2 \cdot 11 \times$ crown

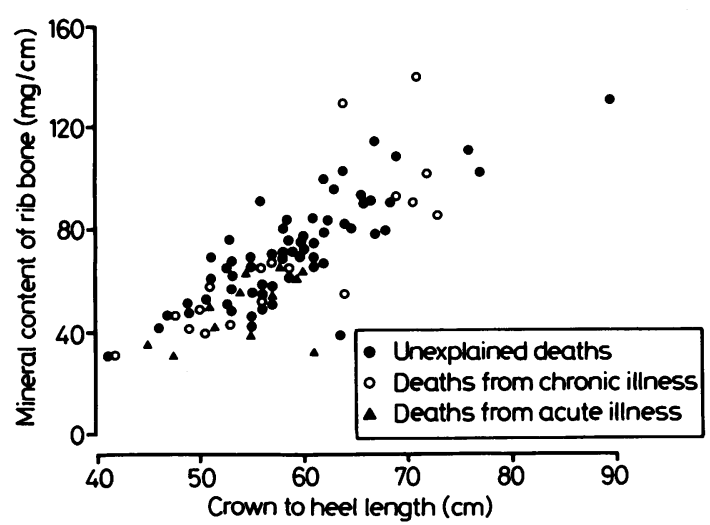

Fig 1 Scattergram of mineral content of rib bone and crown to heel length for individual infants.

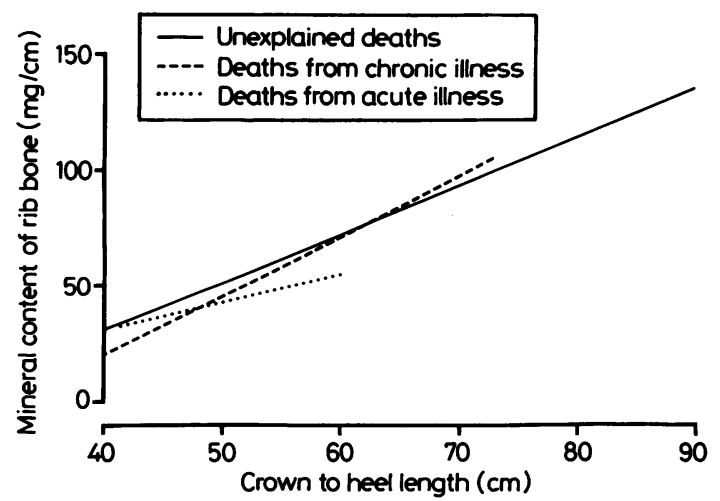

Fig 2 Regression lines for mineral content of rib bone and crown to heel length for the group who died unexpectedly. to heel length $-53 \cdot 29$, in the group who died after acute illnesses it was $2 \cdot 58 \times$ crown to heel length -82.22 , and in the group who died after chronic illnesses it was $1 \cdot 28 \times$ crown to heel length $-20 \cdot 96$.

Nearly three quarters of the 62 unexplained deaths $(72 \%)$ occurred in boys. Thirty five per cent were below the 10th centile for weight. The mineral content of the bone correlated significantly with age $(r=0.761, p<0.001)$ but more closely with crown to heel length $(r=0.816, p<0.001$; fig 2$)$. The mean mineral content of bone/width was 10.40 $\mathrm{mg} / \mathrm{cm}^{2}$ and this proportion did not alter with age.

Just over half of the 18 who died of acute illness $(56 \%)$ were boys and $12(67 \%)$ were below the 10 th centile for weight. Mineral content of bone correlated significantly with age $(r=0.725, p<0.001)$ but more closely with crown to heel length $(r=0 \cdot 814$, $\mathrm{p}<0.001$; fig 2 ). The mean mineral content of bone/width was $10.73 \mathrm{mg} / \mathrm{cm}^{2}$.

Five of the 12 infants who died of chronic illnesses $(42 \%)$ were below the 10 th centile for weight. There was poor correlation between mineral content of bone and age $(r=0.20, p>0.5)$ and between mineral content of bone and crown to heel length $(r=0.50$, $\mathrm{p}<0 \cdot 1)$. These infants had a lower mean mineral content when compared with other infants of similar crown to heel length (paired $t$ test on 12 matched pairs; $p<0 \cdot 01$ ). The mean mineral content of bone/ width was $7.69 \mathrm{mg} / \mathrm{cm}^{2}$

\section{Discussion}

There was an unusually high proportion of unexplained deaths in this series because necropsies on all children dying at home in South Yorkshire are carried out at the Children's Hospital, Sheffield.

In all three groups crown to heel length provided a better correlation with mineral content of bone than age, but crown to heel length and mineral content of bone are both measures of skeletal growth rather than of age. In both the group who died of acute illnesses and the group of unexplained deaths the regression lines for mineral content of bone against age, and mineral content of bone against crown to heel length, lay close to one another (fig 2). These must be interpreted with caution, however, because two thirds of the infants who died of acute illnesses weighed below the 10th centile at the time of death. This might represent either acute weight loss during the terminal illness or indicate otherwise unsuspected illness.

With the above proviso we could find no evidence of decreased mineral content in the ribs in infants dying unexpectedly compared with those dying from acute serious illnesses. This was confirmed by the similar mean values of mineral content of bone/ 
width of rib in the two groups. The results indicate that disturbances in the formation of cartilage seen by others are not longstanding enough or severe enough to cause a measurable reduction in the mineral content of ribs in a study of this size. Reduced mineral content in ribs of infants dying of chronic illnesses was expected as studies in the neonates have shown that undernutrition (relative to the nutrition provided by the placenta when it is functioning correctly) may result in pronounced reductions in the mineral content of bone. ${ }^{4}$

A Horsman and $\mathrm{J}$ Truscott were employed by the Medical Research Council and supported by an External Scientific Staff grant, and S Ryan was supported by a grant from the Special Trustees of the General Infirmary, Leeds.

\section{References}

1 Peterson DR, Benson EA, Fisher LD, Chinn MN, Beckwith JB. Post natal growth and the sudden infant death syndrome. Am J Epidemiol 1974;99:389-94.

2 Sinclair-Smith C, Dinsdale F, Emery J. Evidence of duration and type of illness in children found unexpectedly dead. Arch Dis Child 1976;51:424-9.

3 James JR, Truscott J, Congdon PJ, Horsman A. Measurement of bone mineral content in the human fetus by photon absorpiometry. Early Hum Dev 1986;13:169-81.

4 James JR, Congdon PJ, Truscott J, Horsman A, Arthur R. Osteopenia of prematurity. Arch Dis Child 1986;61:871-6.

Correspondence to Dr S Ryan, Neonatal Intensive Care Unit, Clarendon Wing, The General Infirmary, Leeds LS2 9NS.

Accepted 10 November 1987

\title{
Functional residual capacity related to hepatic disease
}

\author{
A GREENOUGH, J POOL, C BALL, G MIELI-VERGANI, AND A MOWAT \\ Department of Child Health, King's College Hospital, London
}

SUMMARY Functional residual capacity was measured in 20 children (aged 3.1-11.2 years) with liver disease. Children with severe liver disease, regardless of diagnosis, had reduced functional residual capacities ( $<80 \%$ of expected). Children with $\alpha-1$ antitrypsin deficiency had higher functional residual capacities than those with other hepatic diagnoses. Three children had a functional residual capacity $>120 \%$ of expected, all had $\alpha-1$ antitrypsin deficiency.

In childhood $\alpha-1$ antitrypsin deficiency is usually associated with liver disease, but it has been suggested that asthma and bronchitis may be commoner in children over 8 years of age with $\alpha-1$ antitrypsin deficiency. ${ }^{1}$ No respiratory measurements, however, were performed and the authors were unable to comment whether the symptoms were early manifestations of emphysema. ${ }^{1}$

Recently it has become possible to measure functional residual capacity by helium gas dilution reproducibly and accurately even in children as young as 2 years of age. ${ }^{2}$ The aim of the present study, using this technique,,$^{2}$ was to determine if abnormalities of functional residual capacity were present in young children with $\alpha-1$ antitrypsin deficiency. Secondly, by comparing their results with those of children with other hepatic diagnosis, we aimed to determine whether the abnormalities specifically related to $\alpha-1$ antitrypsin deficiency rather than a non-specific effect of hepatic disease.

\section{Patients and methods}

Twenty children attending the paediatric liver service at King's College Hospital were studied. Only one child, who had previously been diagnosed as suffering from asthma, had respiratory symptoms. Twelve children suffered from $\alpha-1$ antitrypsin deficiency (five boys and seven girls, median age 5 years (range 3.1-11.5 years)). Eight other children were also studied: five with biliary atresia, two who had had neonatal hepatitis, and one with congenital hepatic fibrosis. This latter group, who were designated controls, consisted of three boys and five girls with a median age 4.5 years (range $3.5-8.6$ years). The children in both groups were classified into four subgroups according to disease severity (figure).

Ethical permission for the study was granted by King's College Hospital ethical committee and parental consent was obtained.

All children had their functional residual capacity measured by helium gas dilution using a water sealed spirometer (Gould Pulmonet 3) in the paediatric respiratory laboratory. ${ }^{2}$ All recordings were coded and then analysed blind of the child's clinical details. Each child's results were compared with published normal data ${ }^{2}$ or data collected from 60 healthy children of similar ages to the study population. Functional residual capacity was ex- 